\title{
Quality change of mini sweet pumpkins (suppress cultivation, fall planting) during storage at different conditions
}

\author{
Bong-Yun $\mathrm{Oh}^{1 *}$, Gyeong-Suk $\mathrm{Jo}^{1}$, You-Seok Lee ${ }^{1}$, Jeong-Hwa Kang ${ }^{1}$, \\ Mi-Hyang Jang ${ }^{1}$, In-Sik Hwangbo ${ }^{2}$ \\ ${ }^{1}$ Jeollanamdo Agricultural Research and Extension Services, Naju 58213, Korea \\ ${ }^{2}$ Haenam Agricultural Technology Center, Haenam 59044, Korea
}

\section{가을작형 억제재배 미니단호박의 저장조건별 품질 변화}

\author{
오봉윤 $^{1 *} \cdot$ 조경숙 $^{1} \cdot$ 이유석 ${ }^{1} \cdot$ 강정화 $^{1} \cdot$ 장미향 ${ }^{1} \cdot$ 황보인식 $^{2}$ \\ 1전라남도농업기술원, ${ }^{2}$ 해남군농업기술센터
}

\begin{abstract}
We stored sweet pumpkins at $8{ }^{\circ} \mathrm{C}, 12^{\circ} \mathrm{C}, 12^{\circ} \mathrm{C}$ plasma curing and room temperature (control) for 180 days. During this time, the quality characteristics were analyzed within the different groups. No spoiling occurred in either of the storage conditions for up to 120 days, and the marketability was good. After 120 days, spoiling sharply increased by over $70 \%$ in the control group, while in the $12{ }^{\circ} \mathrm{C}$ group it decreased to $20 \sim 60 \%$. Conversely, spoiling was completely absent in the $8^{\circ} \mathrm{C}$ and $12^{\circ} \mathrm{C}$ plasma curing groups during the overall 180 days of storage. The lowest moisture content was found in the $8^{\circ} \mathrm{C}$ group and the quality of the pumpkins was excellent during the entire storage period. The color of pulp was better in the $12^{\circ} \mathrm{C}$ and $12^{\circ} \mathrm{C}$ plasma curing groups, with best results were found in the latest. Both the $8^{\circ} \mathrm{C}$ and $12^{\circ} \mathrm{C}$ plasma curing groups maintained their dark green surface colors, while both the $12{ }^{\circ} \mathrm{C}$ and control groups turned from green to yellow. All groups showed a reduction in their initial hardness, with the $8^{\circ} \mathrm{C}$ group staying the hardest. Soluble solid and mealiness was increased to the storage during 90 days while decreased, that were long to maintain the mealiness texture in the $8^{\circ} \mathrm{C}$ storage pumpkin. The overall acceptability from sensory evaluation was higher in the $12^{\circ} \mathrm{C}$ plasma curing group, when compared to those of the $8^{\circ} \mathrm{C}, 12^{\circ} \mathrm{C}$ and control groups storage conditions.
\end{abstract}

Key words : mini-sweet-pumkin, quality, storage

\section{서 론}

호박(Cucurbita spp.)은 박과에 속하는 일년생 넝쿨식물 로 식용으로 이용되는 것은 동양계 호박(C. moschata Duch.), 서양계 호박(C. maxima Duch.) 페포 호박(C. pepo L.) 등 3 종류로 구분되며. 품종과 성숙도에 따라 열매의 모양, 영양성분 및 맛의 차이가 있다(1). 이들 중 최근 단맛

*Corresponding author. E-mail : bongyun@korea.kr Phone : 82-61-330-2518, Fax : 82-61-336-8117

Received 21 September 2015; Revised 10 November 2015; Accepted 13 November 2015.

Copyright (c) The Korean Society of Food Preservation. All rights reserved.
과 분질감, 색감의 기호도가 높아 소비가 증가하고 있는 단호박은 과실의 크기가 비교적 작아 $0.5 ~ 2 \mathrm{~kg}$ 내외며, 과피 는 진한 녹색이고, 과육은 진한 황색이며, 단단하고, 당도가 높다(2). 단호박은 남미 페루가 원산지인 서양계 호박으로 뉴질랜드, 멕시코, 일본 등에서 주로 재배되었으나, 우리나 라에는 1985년경 일본 수출을 위해 소량씩 계약재배 되어 오다, 기호도가 좋아 수출뿐 아니라 국내 수급을 위해 전남, 경기, 경북, 충북 등 재배면적이 꾸준히 증가하게 되었다(2).

건강을 중요시하는 현대인들에게 웰빙식품 소재로 단호 박은 제과제빵용 분말가루(3), 국수(4), 젤리(5), 설기떡(6), 식혜(7), 쿠키(8), 호상요구르트(9), 스폰지케잌(10), 머핀 (11), 식빵(12) 등 다양하게 활용되고 있으며, 그 소비가 꾸준히 증가할 것으로 전망된다. 
국내에서 재배되고 있는 단호박은 가용성 고형분이 $10 \sim 12^{\circ} \mathrm{Brix}$ 내외로 종래의 늙은호박보다 높을 뿐만 아니라 영양성분 면에서도 우수하여(2), 카로티노이드 함량은 단 호박의 경우 $1.22 \mathrm{mg} \%$ 로 늙은호박의 $0.5 \mathrm{mg} \%$ 보다 월등히 높고, 비타민C 함량도 단호박은 $3.6 \mathrm{mg} \%$ 인데, 늙은호박은 $0.27 \mathrm{mg} \%$ 이며, 무기질은 $\mathrm{Ca}, \mathrm{Zn}, \mathrm{Fe}, \mathrm{K}, \mathrm{Mg}, \mathrm{Na}, \mathrm{P}$ 등도 단호박이 2 배 가량 더 함유할 뿐만 아니라 유리당, 아미노산 도 더 높게 함유되어 영양적 가치가 매우 높다고 보고되어 있다(13).

단호박 품종은 보짱(미니), 구리지망(일반), 만차랑(대 형), 아지헤이, 시로지망, 아까지망 등이 국내에서 재배되고 있으며(14), 이중 과중이 $500 \mathrm{~g}$ 내외로 크기가 작고 강분질 감으로 밤호박 또는 미니단호박이라 불리는 품종 “보짱”은 전남지역 해남군과 함평군에 지역특화작목으로 보급되어 약 $384 \mathrm{ha('11년)} \mathrm{재배되고} \mathrm{있으며,} \mathrm{이는} \mathrm{전국대배} 21.7 \%$ 를 점유하고 있다. 국내산 단호박은 대부분 7 8월에 집중적으 로 생산되며, 이 시기에 과잉공급으로 인해 가격하락은 재 배 및 판매 농가의 어려움의 원인이 되고 있다 $(2,14)$.

최근 전남 해남군과 함평군에서는 단호박 재배작형으로 봄에 반촉성 재배한 것을 5월 하순부터 7월 초순까지 수확 하며, 여름에 노지 조숙재배한 것은 7월 초부터 8월 하순까 지 수확하며, 이때 수확한 것은 저장하여 11월 말까지 유통 되고 있다. 가을에는 억제재배로 11 월 말부터 12 월 중순까 지 수확하며, 이들은 상온에서 후숙, 저장하면서 이듬해 2월까지 극히 일부에서 저장-유통하고 있으며, 뉴질랜드 등 수입산이 2 6월까지 대부분 유통되고 있다(15).

이에 국내산 단호박의 연중 생산체계를 구축하기 위해, 가을작형 억제재배한 것을 12 월에 수확하여 이듬해 5월까 지 저장유통 할 수 있다면, 단호박을 안정된 가격으로 연중 수급할 뿐 아니라 수출품목으로 성장시킬 수 있으며(2), 농가소득 향상에 기여될 것으로 판단된다.

지금까지 보고된 단호박 저장성 연구에서 $\operatorname{Han}$ 등(16)은 ‘밤호박 저장온도와 습도가 품질에 미치는 영향, Lee 등 (17)은 '단호박 보짱의 저장온도 및 저장기간에 따른 과실 특성, 연구로 8월에 수확한 단호박을 11 월까지 저장하는 연구가 전부이며, 가을작형 억제재배한 단호박 저장성 연 구는 전무한 실정이다.

그러므로, 본 연구는 가을작형 억제재배한 단호박을 봄 작형 단호박이 수확되는 6월까지 상품성 있는 미니단호박 을 유통 출하하기 위해 농가 현장에서 관행 2 개월 저장하는 조건에서 3 개월 더 연장시킬 수 있는 저장조건을 구명하고 자 $8^{\circ} \mathrm{C}, 12^{\circ} \mathrm{C}, 12^{\circ} \mathrm{C}$ 플라즈마 큐어링 저장고 및 대조구로 농가 비가림 시설내 실온, 네 가지 저장조건에서 180 일간 저장하면서 30 일 간격으로 시료를 취하여 품질 특성을 분 석하였다.

\section{재료 및 방법}

\section{실험재료}

본 실험에 사용한 미니단호박의 품종은 '보짱'이며, 전남 해남군 계곡면에 소재한 농가에서 2014년 8월 15일 파종하 여 9월 10일 정식하였고, 10월 9 10일 수정후 착과시켜 가을에 재배된 것이며, 착과 후 60 일 된 것을 일괄 수확하였 다. 수돗물에 차염소산나트륨 $150 \mathrm{ppm}$ 이 되게 희석하여 세척 후 수돗물로 1회 헹굼하여 물기가 제거된 상태에서 $520 \times 366 \times 322 \mathrm{~mm}$ 의 노란색 플라스틱 과일 박스에 30 개씩 담아 시료를 준비하였다. 해남군 밤호박농업회사법인이 보 유하고 있는 $74 \mathrm{~m}^{2}$ 면적의 저장고에서 장기저장을 위한 큐어링 처리로 $30^{\circ} \mathrm{C}, 7$ 일간 건조 처리하여, 수확당시 평균 중량의 $4 \sim 5 \%$ 감량된 상태(18)의 것을 저장하였다.

\section{저장조건}

농가에서 보유하고 있는 저장고 3 개를 각 온도별로 세팅 하였으며, 저장기간 중 온습도 조건은 $8^{\circ} \mathrm{C}$ 저장고는 평균 상대습도 $62 \%, 12^{\circ} \mathrm{C}$ 저장고는 $63 \%, 12^{\circ} \mathrm{C}$ 저장고에 플라즈 마(공기 중 헬륨, 산소, 질소 가스에 에너지를 가하여 이온 화된 가스를 생성) 큐어링 장치로 (주워터링크(한국)에서 제공한 장치를 설치한 저장고는 상대습도가 $65 \%$ 였다. 플라 즈마 발생원 세부사항은 입력전압 : $220 \mathrm{~V}$, 출력전압 : 3.2 $\mathrm{kV}$, 입력 주파수 $60 \mathrm{~Hz}$, 출력 주파수 $18 \mathrm{kHz}$, 유전체 재질은 알루미나 $99.9 \%$ 세라믹, 방전자 재질은 $\mathrm{Cu}$ 와 $\mathrm{Pt}$ 이었으며, 유전체 격벽 방전방식이었다. 대조구인 실온의 평균 상대 습도는 $64 \%$ 였다. 180 일(6개월) 동안 저장하면서 30 일 간격 으로 시료를 취하여 품질특성을 분석하였다. 처리구별 개 체 수는 30 개씩 3 처리, 시료보관을 위해서는 농가에서 저 장, 유통 중 사용하고 있는 $520 \times 366 \times 322 \mathrm{~mm}$ 의 플라스틱 과일 박스를 이용하였으며, 저장 기간별로 플라스틱 상자 당 5 개씩 시료를 취하여 품질 특성을 분석하였다.

\section{부패율 및 상품성}

미니단호박에 부패율은 곰팡이가 발생되거나 과피 부분 에 흑변, 무름 현상이 관찰되면 부패과로 판단하였으며, 총 개체수에 대한 전과의 개체수를 백분율로 나타냈다. 상 품성은 저장 초기 단호박의 외관적 특색인 진한 녹색과 윤기 있는 정도를 7점 척도로 7점(매우 좋음), 6점(좋음), 5점(조금 좋음), 4점(보통), 3점(조금 안 좋음), 2점(안 좋음), 1점(매우 안 좋음)으로 평가하였다.

\section{수분함량}

저장 기간별 단호박의 수분함량을 측정하기 위해 각 시 료의 중심부에서 동일하게 $2 \mathrm{~mm}$ 두께로 자른 후 $10 \mathrm{~g}$ 을 취하여 $105^{\circ} \mathrm{C}$ 상압가열방법으로 12 시간 건조 후 시료가 항량 될 때 초기 무게에서 건조된 무게를 제외하여 초기 
시료 무게에 대한 백분율로 나타냈다.

색 도

단호박 과피 및 과육의 색도는 단호박을 2 등분하여 과피 는 볼록한 중앙부위를, 과육은 꼭지부분의 절단된 단면 윗 부분을 색차계(JS-555, Color Techno systems JP/JX-7 Co., Ltd., Tokyo, Japan)로 하여 밝기 명도 L값, 적색도 a 값, 녹색도 $-\mathrm{a}$ 값, 황색도 $\mathrm{b}$ 값을 5 회 반복 측정하였고, 그 평균값 을 나타냈다. 사용한 표준백 판의 $\mathrm{L}, \mathrm{a}, \mathrm{b}$ 값은 각각 98.28 , -0.97 및 0.28 이었다.

\section{경 도}

경도(hardness)의 측정은 texture analyser(TA-XT2, Stable Micro system Ltd., Haslemer, UK)를 이용하여 측정하였다. 단호박 시료는 2 등분으로 절단하여 절단부위를 바닥에 뒤 집어 놓고, 시료의 중앙부 윗부분을 $5 \mathrm{~mm}$ diameter probe( $\Phi$ 2)로 눌러서 측정하였다. Test mode는 compression, pre-test speed $5.0 \mathrm{~mm} / \mathrm{sec}$, test speed $3.0 \mathrm{~mm} / \mathrm{sec}$, post-test speed $5.00 \mathrm{~mm} / \mathrm{sec}$, trigger force $10.0 \mathrm{~g}$ 로 하였으며, 그래프 중 최고의 피크점을 기준으로 하여 $\mathrm{g}$-force로 나타냈다.

\section{가용성 고형분}

미니단호박의 가용성 고형분은 시료 $10 \mathrm{~g}$ 을 취하여 핸드 믹서기(Shinil Co., Seoul, Korea)로 2분간 분쇄 균질화한 후 무명 거즈로 착즙하여 hand refractometer(PAL-1, Atago Co., Ltd., Tokyo, Japan)를 이용하여, 5 회 측정하였다.

\section{전분질 분리}

각 저장조건별로 저장했던 미니단호박 시료 $10 \mathrm{~g}$ 을 정확 하게 취하여 증류수 $100 \mathrm{~mL}$ 을 이용하여 $\mathrm{Han}$ 등(19)의 알칼 리 침전법을 변형하여 전분질을 추출하였다. 먼저 시료와 증류수 $50 \mathrm{~mL}$ 를 electric mixer(SFM-555SP, Shinil, Co., Seoul, Korea)에 넣고 2분간 균일하게 분쇄한 후 무명 거즈 천으로 건데기는 걸러 내고 미니단호박에 함유된 전분질을 통과시켰다. 나머지 증류수 $50 \mathrm{~mL}$ 를 이용하여 여분의 전분 질을 씻어 $250 \mathrm{~mL}$ 비이커에 씻어 모은 후 12시간 동안 $4^{\circ} \mathrm{C}$ 냉장고에서 냉침하였다. 이 때 맑은 상층액과 무거운 전분침전물로 나뉘는데, 맑은 상층액은 제거하고, 아래 침 전된 하얀 전분질만을 취해서 $80^{\circ} \mathrm{C}$ 에서 12 시간 건조 후 무게를 측정하여, 단호박 전분질 함량은 단호박 생체 시료 $10 \mathrm{~g}$ 당 건조 전분질 무게를 측정하여 초기 무게에 대한 백분율로 나타냈다.

\section{관능평가}

단호박 저장조건별 저장 중 품질에 대한 관능평가는 전 남농업기술원 식품경영연구소 식품연구팀의 연구원 10 명 의 패널 요원을 대상으로 실험의 목적과 평가항목에 대해
설명한 다음 기호도 평가를 실시하였다. 관능평가용 단호 박은 세척 후 8 등분하여 스팀찜기로 10 분간 쪄서 폴리에틸 렌 일회용 접시에 담아 시료를 제공하였다. 평가항목은 색 (color), 향(order), 단맛(sweet taste), 분질감(mealiness texture) 및 전반적인 기호도(overall acceptability)에 대하여 7점 척도법(1 매우 안좋다, 4 보통이다 7 매우 좋다)으로 평가하였다.

\section{통계처리}

실험분석하여 얻어진 결과 자료의 통계분석은 Microsoft Office 2007 Excel program을 이용하여 평균표표준편차로 나타냈으며, 관능검사 결과는 통계분석용 SPSS(18.0, SPSS Inc, Chicago, IL, USA) package program을 이용하여 분산분 석을 실시하였고, 유의차가 있는 경우는 $\mathrm{p}<0.05$ 수준에서 Duncan's multiple range test를 이용하여 차이에 대한 유의 성을 검정하였다(20).

\section{결과 및 고찰}

\section{상품성 및 부패율}

가을에 재배한 “보짱” 품종의 미니단호박을 12 월 중순에 수확하여 $30^{\circ} \mathrm{C}$ 에서 7 일간 후숙한 후 농가현장에서 적용하 고 있는 네 가지 저장조건에 따라 $8^{\circ} \mathrm{C}, 12^{\circ} \mathrm{C}, 12^{\circ} \mathrm{C}$ 플라즈마 큐어링 처리 및 대조구로 실내 온도에서 저장하면서 30 일 간격으로 시료를 취하여, 품질특성을 분석하였다. 미니단 호박 시료의 외관적 특성의 상품성 변화를 조사하여 Fig. 1에 나타냈다. 단호박의 상품성은 7점 척도법으로 판단하였다. 저장기간 90 일까지 상품성을 유지하는 저장조건은 대조구 (실온), $8^{\circ} \mathrm{C}, 12^{\circ} \mathrm{C}$ 및 $12^{\circ} \mathrm{C}$ 플라즈마 큐어링 처리 순이었으며, 저장 120 일 이후에는 $8^{\circ} \mathrm{C}, 12^{\circ} \mathrm{C}, 12^{\circ} \mathrm{C}$ 플라즈마 큐어링 처리 및 대조구로, 실온에서는 120 일 이후 급격하게 상품성이

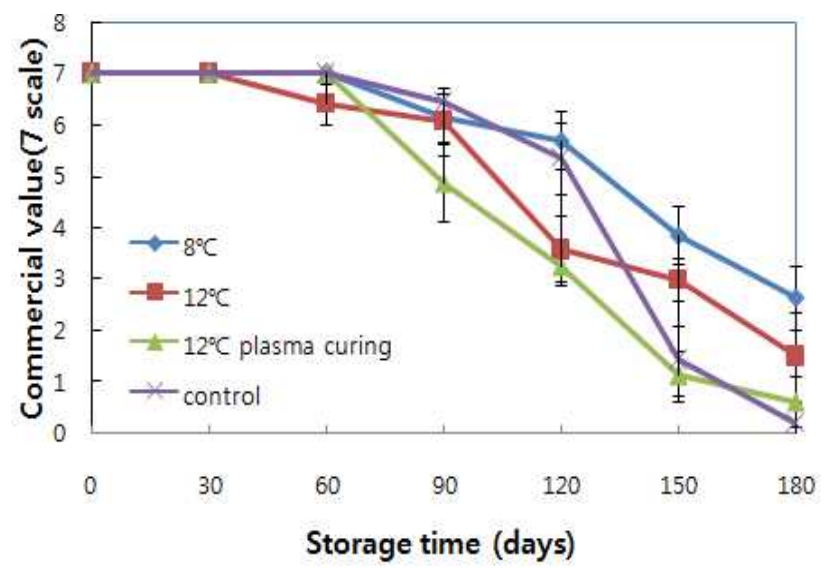

Fig. 1. Changes in the commercial value of mini sweet pumpkins during storage at different temperature conditions.

Values represent the mean $\pm \mathrm{SD}(\mathrm{n}=7)$. 
떨어졌는데, 이는 본 실험을 수행하는 기간이 1월에서 6월 까지로 저장 초기에는 실온 온도가 $5 \sim 10^{\circ} \mathrm{C}$ 정도 낮은 기온 이 점차 기간이 길어질수록 기온 상승에 따라서 단호박의 저장조건 실온의 온도 상승에 영향을 미쳐 급격한 상품 저하 원인이 되는 것으로 판단되었다. 상품성 4점 이상을 유지하기 위한 저장조건은 $8^{\circ} \mathrm{C}$ 에서는 150 일, 대조구 상온 (겨울에서 봄, $1 \sim 4$ 월)은 120 일, $12^{\circ} \mathrm{C}$ 에서는 90 일이었다. 1 $2{ }^{\circ} \mathrm{C}$ 플라즈마 큐어링 처리 조건은 2 개월 이후에 급격하게 상품성이 떨어졌으며, 이는 플라즈마 큐어링 처리시 저장 고내에 이취가 발생하며, 저장된 단호박에 이취가 베이고, 단호박 표면에 부패는 아니지만 검은 반점이 생긴 것을 관찰할 수 있었다. Lee 등(17)의 보고에서 미니단호박 보짱 의 저장온도 및 저장기간에 따른 과실 특성에서도 단호박을 60 일 이상 저장시에는 $8^{\circ} \mathrm{C}$ 와 $12^{\circ} \mathrm{C}$ 에 저장하는 것이 적당하 며, 저장 후에는 상온에서 유통되는 기간을 최소화할 필요 가 있을 것으로 제언하였다. $12^{\circ} \mathrm{C}$ 에서 저장한 단호박은 저 장 3 개월부터 과피가 황색으로 변하기 시작하였으며, 대조 구인 실온과 $8^{\circ} \mathrm{C}$ 에서 저장한 것에 비해 상대적으로 외관상 상품성이 낮게 나타났지만, 150 일까지 4점(보통이다)의 상 품성을 유지하였다.

저장 기간 중 단호박의 부패율은 Fig. 2 와 같다. 저장 120 일까지 전 실험구에서 부패율은 나타나지 않았으며, 저 장 150 일째 $12^{\circ} \mathrm{C}$ 에서 $25.6 \%$, 실온에서 $70 \%$ 가 나타났는데, 이는 $\operatorname{Han}$ 등(16)의 보고에서 단호박 과육에 피해를 주는 병해는 역병(Phytophthora capsici)과 탄저병(Colletofrichun lagenarium)으로 특히 수확 직후 및 저장 초기에 발생되는 초기부패는 미리 침투된 역병균이 원인이 되는 것으로 보고 하고 있는데, 본 저장 실험을 위해 시료 미니단호박을 150 $\mathrm{ppm}$ 차염소산나트륨에 세척한 후, $30^{\circ} \mathrm{C}$ 에서 7 일간 건조하 여 저장 전에 큐어링 처리를 하여 부패율이 낮은 것으로 판단되었다. 또한 부패율은 습도보다 온도의 영향을 더 받

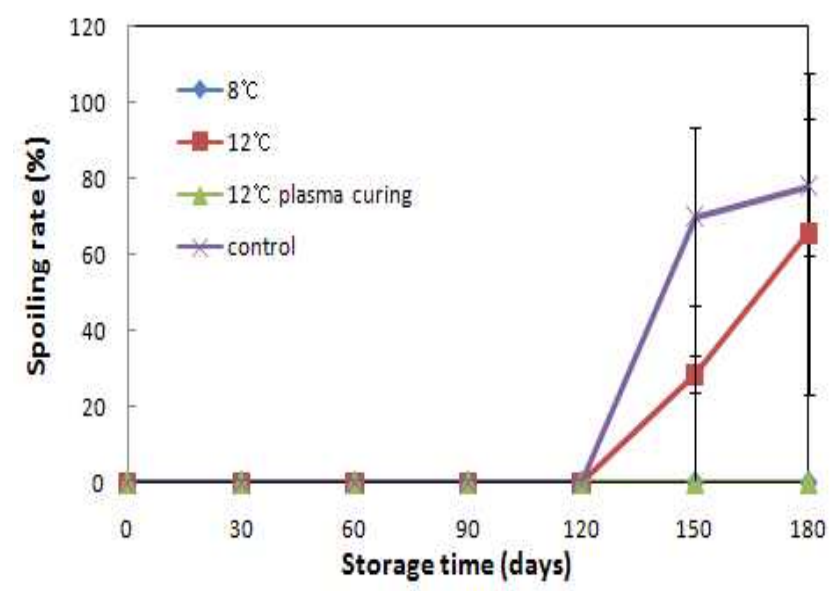

Fig. 2. Changes in the spoiling rate of mini sweet pumpkins during storage at different temperature conditions.

Values represent the mean $\pm \mathrm{SD}(\mathrm{n}=7)$.
는 것으로 부패율면에서 $12^{\circ} \mathrm{C}$ 에서 습도 $40 \sim 60 \% \mathrm{RH}$ 저장이 적합한 것으로 보고(16) 하였으나, 본 연구에서는 습도 $60 ~ 65 \% \mathrm{RH}$ 범위에서 저장 150 일째 실온의 저장조건 $20^{\circ} \mathrm{C}$ 이상에서 급격한 부패율 $70 \%$ 이상을 나타냈으며, $12^{\circ} \mathrm{C}$ 에서 저장 150 일째 $28.6 \%$ 의 부패율이 나타났다. $8^{\circ} \mathrm{C}$ 저장조건과 $12^{\circ} \mathrm{C}$ 플라즈마 큐어링 처리에서는 과피 표면에 검은 반점이 나타났지만, 두 저장조건에서는 곰팡이 등이 번식하여 썩 어 물러지는 등의 부패 현상은 저장 180 일까지도 나타나지 않았다.

\section{수분함량}

네 가지 저장조건별 저장 기간 중 미니단호박의 수분함 량 변화는 Fig. 3 과 같다. 수분함량은 저장 초기 $74.13 \%$ 에서 조건별로 저장 30 일에는 $64.83 ~ 65.02 \%$ 로 전체적으로 약 $10 \%$ 가량 감소하였으며, 그 이후 저장기간 중 약간 증가하 는 경향이었다. 미니단호박의 수분함량 변화는 저장기간이 경과함에 따라 상품성과 비교시, 수분함량이 높은 것은 상 품성이 낮아졌으며, 수분함량이 낮으면 상대적으로 상품성 은 높게 나타나 전체적으로 상품성이 높았던 저장조건에서 수분함량도 전체적으로 낮았으며, 상품성이 낮았던 $12^{\circ} \mathrm{C}$ 플라즈마 큐어링 처리조건에서는 상대적으로 다른 저장조 건에 비해 수분함량은 $70 \%$ 이상으로 높게 분석되었다. 반 면, 수분함량이 낮은 $8^{\circ} \mathrm{C}$ 저장에서 상품성 가장 우수하였고, 부패율이 가장 낮았다.

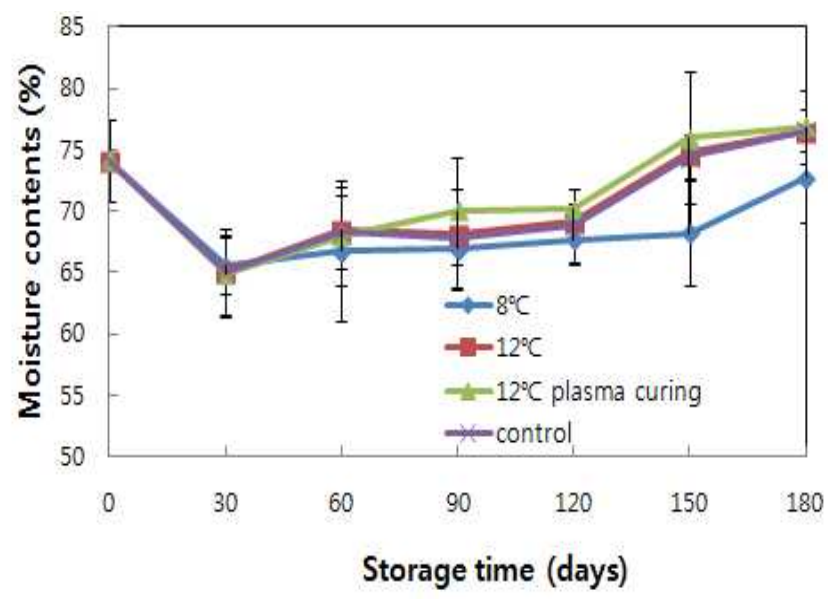

Fig. 3. Changes in the moisture contents of mini sweet pumpkins during storage at different temperature conditions.

Values represent the mean $\pm \mathrm{SD}(\mathrm{n}=7)$.

과피 및 과육 색도

저장기간 중 미니단호박 과피의 색도 변화는 Fig. 4 와 같다. 미니단호박의 과피는 진한 녹색으로 저장 초기 과피 의 색도 명도 $\mathrm{L}$ 값은 25.93 , 녹색도 $-\mathrm{a}$ 값은 -3.4 , 황색도 $\mathrm{b}$ 값은 3.16 이었다. 명도 L 값은 저장 60 일까지 거의 변화가 없었으며, 60 일에서 90 일까지 완만하게 증가하다 150 일까 지 증가하였으며, 그 이후에는 급격히 감소하였으며, 명도 
는 $8^{\circ} \mathrm{C}$ 에서 변화가 가장 적었다. $12^{\circ} \mathrm{C}$ 와 $12^{\circ} \mathrm{C}$ 플라즈마 큐어 링 처리구는 거의 비슷한 색 변화를 보였고, 대조구 실온에 서 저장했을 때 저장 120 일 이후에 가장 높은 변화를 나타냈 다. 과피의 녹색도 $-\mathrm{a}$ 값은 저장 중 90 일까지는 약간 감소 하였으며, 그 이후에는 완만하게 증가하였다. 저장조건별 로 살펴보았을 때 저장기간 중 녹색도를 잘 유지하는 조건 으로는 $12^{\circ} \mathrm{C}$ 플라즈마 큐어링 저장조건이었으며, 그 다음 $8{ }^{\circ} \mathrm{C}, 12^{\circ} \mathrm{C}$ 순서로 저장기간 중 과피의 녹색을 유지하였다. 대조구 실온에서 저장했을 때, 저장 120 일 이후에는 기온상 승으로 온도가 상승함에 따라 저장한 미니단호박의 과피 색이 진한녹색에서 황색과 적색으로 급격하게 변하여 저장 180 일에는 a 값 2.56 까지 증가하여 색이 변하는 것을 관찰할 수 있었다. 수확 후 과일과 채소에서 일어나는 화학적 변화 중에서 초록색 색소인 클로로필이 파괴되면서 주황색의
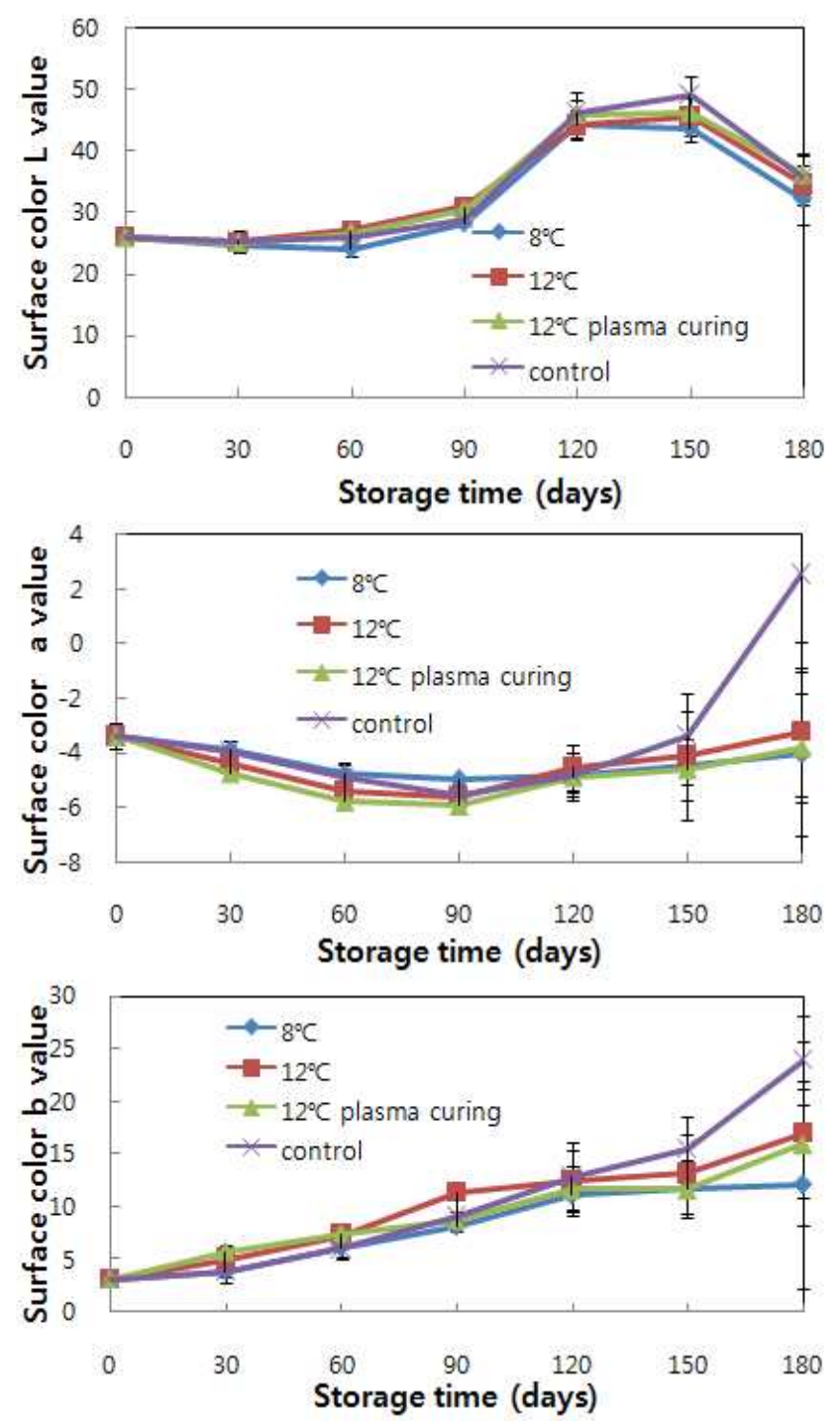

Fig. 4. Changes in the surface color $L$, $a$, and $b$ value of mini sweet pumpkins during storage at different temperature conditions.

Values represent the mean $\pm \mathrm{SD}(\mathrm{n}=7)$.
카로티노이드가 생성되어 과실의 색이 변하는 것이 일반적 으로 알려져 있는데 $(17,21)$, 단호박도 저장기간 중 저장온 도에 비례하여 외관상 색의 변화를 나타냈다.

과피의 황색도 $\mathrm{b}$ 값은 저장기간 중 완만하게 증가하였으 며, $8{ }^{\circ} \mathrm{C}, 12^{\circ} \mathrm{C}$ 플라즈마 큐어링 조건, $12^{\circ} \mathrm{C}$, 대조구 실온 저장조건 순으로 색도 변화가 적었으며, 저장 중 미니단호 박의 황색도 $\mathrm{b}$ 값은 저장 중 상품성과 비교시 황색도가 높아지면 상품성은 낮아지는 경향을 나타냈다. Lee 등(17) 저온에 저장할수록 과피의 황변이 억제되었다고 하였다.

미니단호박의 저장 중 과육의 색도 변화는 Fig. 5와 같다. 미니단호박의 저장 초기 과육의 색도는 명도 L 값은 73.33, 적색도 $\mathrm{a}$ 값은 3.51 , 황색도 $\mathrm{b}$ 값은 77.42 이었다.

저장 기간 중 명도 $\mathrm{L}$ 값은 완만하게 서서히 감소하였으 며, 적색도 a 값은 저장 전 기간 동안 증가하여 저장 120 일에
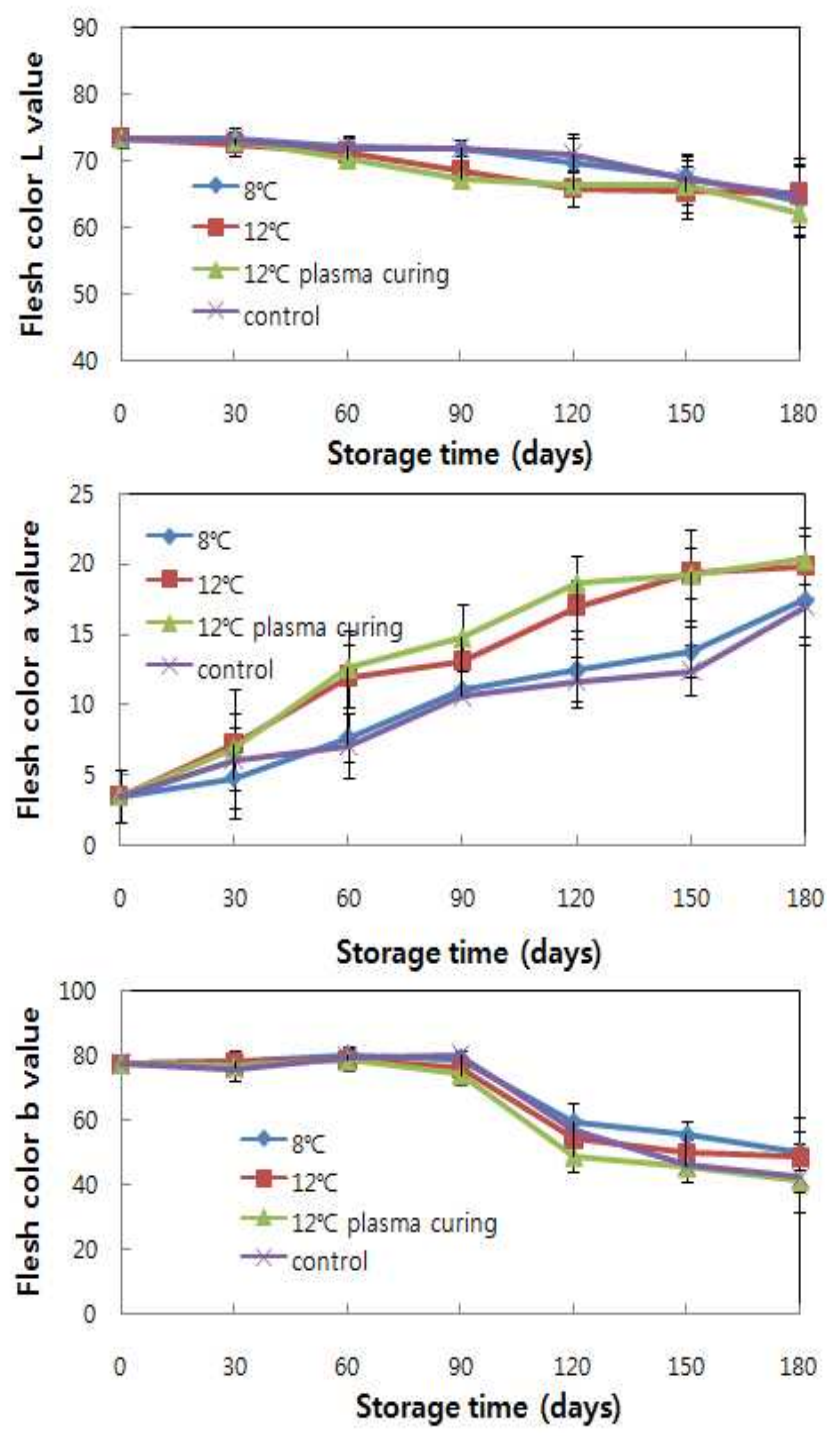

Fig. 5. Changes in the flesh color $\mathrm{L}, \mathrm{a}$, and $\mathrm{b}$ value of mini sweet pumpkins during storage at different temperature conditions.

Values represent the mean $\pm \mathrm{SD}(\mathrm{n}=7)$. 
는 $12^{\circ} \mathrm{C}$ 플라즈마 큐어링 조건이 $18.67,12^{\circ} \mathrm{C}$ 에서는 17.06 , $8^{\circ} \mathrm{C}$ 에서는 12.50 , 대조구 실온에서는 11.65 까지 증가하였으 며, 그 이후 저장기간에도 완만하게 증가하였다. 황색도 $\mathrm{b}$ 값은 저장 90 일까지 전 저장조건에서 완만하게 증가하였 으나 그 이후 120 일까지 급격하게 감소하였으며, 180 일까 지 완만하게 감소하였다. 이는 Han 등(16)의 보고와 비슷한 결과를 나타냈다. 단호박의 과육 색도 $\mathrm{a}$ 와 $\mathrm{b}$ 값은 호박의 카로틴 함량에 영향을 받으며, 단호박에는 lutein의 비율이 크고, $\alpha$ 와 $\beta$-carotene외에 antheraxanthin과 violaxanthin이 함유하는 것으로 보고하였다(22). 단호박 저장기간 90 일까 지 이들 성분들이 증가함으로써 과육의 색도가 변하는 것으 로 사료된다.

\section{경 도}

과육 경도의 저장기간 중 변화는 Fig. 6과 같다. 초기 $17,389.5 \mathrm{~g}$ 에서 저장 중 저장조건별 전체적으로 완만하게 감소하는 경향을 나타냈으며, 저장 90 일까지는 $8^{\circ} \mathrm{C} 16,714$ $\mathrm{g}$ 와 상온 $16,604 \mathrm{~g}$ 로 서서히 감소하였으며, $12^{\circ} \mathrm{C}$ 와 $12^{\circ} \mathrm{C}$ 플라즈마 큐어링 조건은 $15,652 \mathrm{~g}$ 와 $15,617 \mathrm{~g}$ 로 저장 온도가 높을수록 과육이 연화되어 경도가 감소하게 되었으며, 감 소폭이 더 크게 나타났다. 90 일 이후에는 대조구인 실온 저장조건은 기온 상승으로 저장온도가 상승하여 급격하게 경도가 낮아졌으며, $8^{\circ} \mathrm{C}$ 저장조건이 180 일까지 저장 전 기 간 동안 감소폭이 가장 적었다.

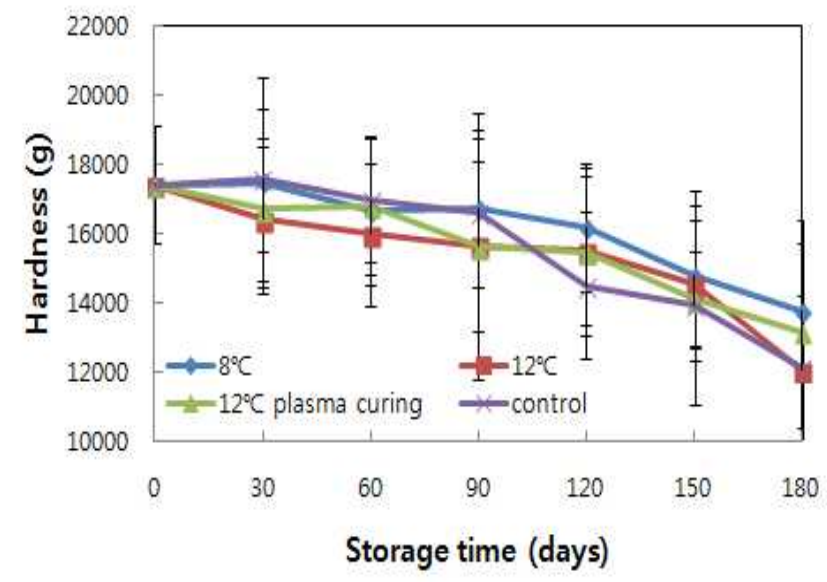

Fig. 6. Changes in the hardness of mini sweet pumpkins during storage at different temperature conditions.

Values represent the mean $\pm \mathrm{SD}(\mathrm{n}=7)$.

\section{가용성 고형분}

저장 중 가용성 고형분 함량 변화는 Fig. 7과 같다. 본 연구에 사용된 미니단호박의 저장 초기 가용성 고형분은 수확 직후 약 $12 \sim 13.7^{\circ} \mathrm{Brix}$ 였는데 $30^{\circ} \mathrm{C}$ 에서 7일간 큐어링 처리하면서 약 $3^{\circ} \mathrm{Brix}$ 가 증가하여 저장 초기는 $16.1^{\circ} \mathrm{Brix}$ 한(15)의 연구 보고와 비슷한 결과이며, $8^{\circ} \mathrm{C}$ 와 대조구 실온 조건에서 저장 90 일까지 증가하여 가용성 고형분 함량이
21.58 과 22.18 까지 증가하다. 그 이후에 $8^{\circ} \mathrm{C}$ 에서는 180 일까 지 완만하게 감소하였으며, 실온에서는 급격하게 감소하여 저장 180 일에는 $16.4^{\circ} \mathrm{Brix}$ 였다. $12^{\circ} \mathrm{C}$ 저장조건에서는 60 일 까지 $21.24^{\circ} \mathrm{Brix}$ 로 증가하다 그 이후 저장 180 일에는 $18.64^{\circ} \mathrm{Brix}$ 까지 서서히 감소하였으며, $12^{\circ} \mathrm{C}$ 플라즈마 큐어 링 저장조건에서는 저장 30 일에 $19.88^{\circ} \mathrm{Brix}$ 까지 증가하다 저장기간 중 $18.01^{\circ} \mathrm{Brix}$ 로 서서히 감소하였다.

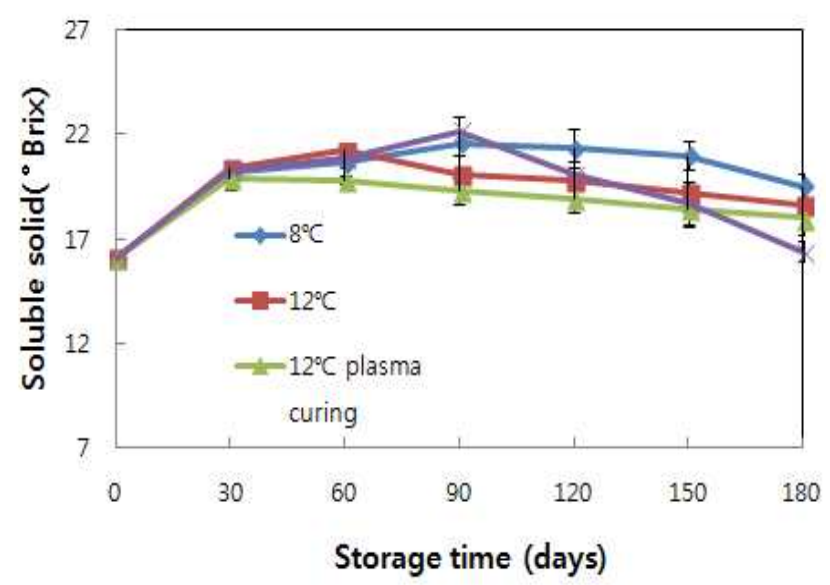

Fig. 7. Changes in the soluble solid of mini sweet pumpkins during storage at different temperature conditions.

Values represent the mean $\pm \mathrm{SD}(\mathrm{n}=7)$.

\section{전분질 함량}

저장조건별 전분질 함량 변화는 Fig. 8과 같다. 초기 전분 질 함량은 $11.33 \%$ 였으나 30 일 저장시에 증가하여 13.71 16.69\%였으며, 그 이후 저장기간 중에 급격하게 감 소하였고, 감소 폭은 저장온도의 영향으로 $8^{\circ} \mathrm{C}, 90$ 일까지는 대조구인 실온, $12^{\circ} \mathrm{C}$ 및 $12^{\circ} \mathrm{C}$ 플라즈마 큐어링 처리조건 순으로 낮았으며, 90 일 이후에는 $8^{\circ} \mathrm{C}, 12^{\circ} \mathrm{C}$, 대조구 실온,

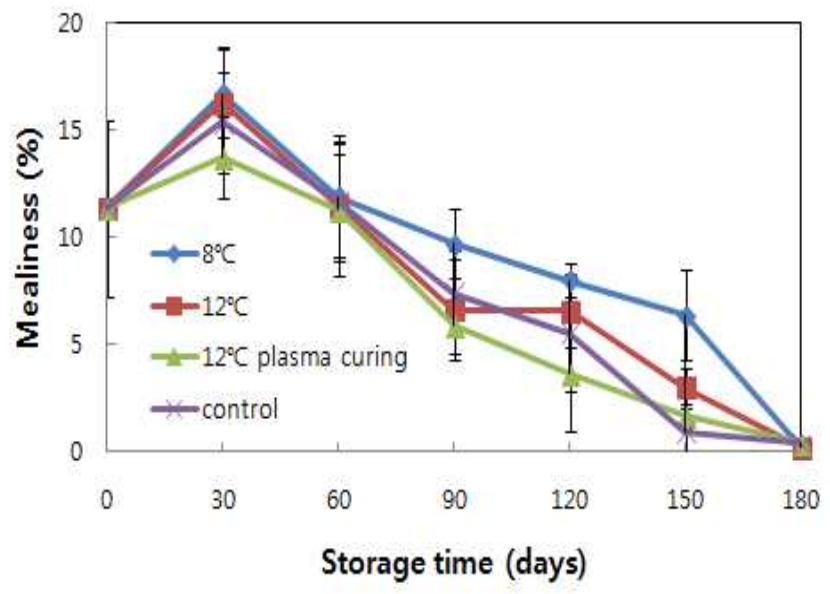

Fig. 8. Changes in the mealiness of mini sweet pumpkins during storage at different temperature conditions.

Values represent the mean $\pm S D(n=7)$. 
$12^{\circ} \mathrm{C}$ 플라즈마 큐어링 조건 순으로 감소폭이 낮았다. 전분 질 함량 감소는 미니단호박 저장 기간 중 전분질이 당화되 어 저장일적기간 동안 가용성 고형분은 증가하는 경향을 나타내며(17), 전분질이 당화되는 정도는 관능평가시 분질 감에 영향을 미치며, 분질감이 어느 정도 선호할 수 있는 기호도가 느껴지려면 전분질 $6 \%$ 이상은 되어야 관능평가 시 4점 이상의 기호도가 되는 것으로 판단되었다. 150 일 이상 저장 전 기간 중 전분질과 가용성 고형분 함량이 유지 되는 저장조건은 $8^{\circ} \mathrm{C}$ 로, 가을작형 억제재배 미니단호박의 적정 저장온도는 $8^{\circ} \mathrm{C}$ 가 적당할 것으로 판단되었다.

\section{관능평가}

저장 조건별 미니단호박의 저장 중 관능평가시 기호도 변화는 Table 1 과 같다. 저장하기 위해 수확한 단호박을 $30^{\circ} \mathrm{C}, 7$ 일간 큐어링했을 당시 저장 전 초기 시료는 색 5.4, 풍미 5.2, 단맛 5.0, 분질감 6.5 , 전체적인 기호도는 5.8 이였 는데, 이들 단호박은 저장함에 따라 90 일까지 색에 대한 기호도는 증가·유지되었으며, 그 이후에는 약간 감소하였 다. 이는 저장 중 단호박의 적색도 $\mathrm{a}$ 값의 저장 중 증가하는 경향과 황색도 $\mathrm{b}$ 값의 증가 후 감소하는 경향으로 이들 색감은 식욕을 돋구며, 관능평가시 색에 대한 기호도가 높 아졌으며, 저장 중 변화 패턴이 일치하는 결과였다.
단은 저장 60 일까지 네 가지 저장조건 모두 증가하였으 며, 그 이후에는 감소하였다. 감소하는 경향은 $8^{\circ} \mathrm{C}, 12^{\circ} \mathrm{C}$, 대 조구 실온, $12^{\circ} \mathrm{C}$ 플라즈마 큐어링 조건 순으로 감소하는 변화 폭이 적었다. 분질감은 저장초기에 가장 높았으며, 그 이후에는 서서히 감소하는 경향을 보였으며, $8^{\circ} \mathrm{C}$ 저장조 건에서는 150 일까지 기호도 5 점을 유지하였다. 이는 단호 박 초기 분질감을 주는 전분질이 저장 중 단맛을 내는 단당 류로 변화하는 것으로 판단되었으며(22), 60 일 이후에는 단맛이 감소하였으며, 특히 $12^{\circ} \mathrm{C}$ 플라즈마 큐어링 처리구 에서 급격하게 감소하였으며, 분질감 및 전체적인 기호도 에서도 유사한 경향을 나타냈다. 가용성 고형분 함량은 저 장 중 계속 증가하였으나, 단맛과 분질감이 적정할 때 미니 단호박에 대한 전체적 기호도가 높았으며, $8^{\circ} \mathrm{C}$ 와 $12^{\circ} \mathrm{C}$ 저장 조건에서는 150 일까지 4 점 이상이었으나, $12^{\circ} \mathrm{C}$ 플라즈마 큐어링 조건과 대조구 상온은 90 일 이상에서는 4점 이하로 기호도가 낮아졌다. 특히 $12^{\circ} \mathrm{C}$ 플라즈마 큐어링 조건에서 저장한 미니단호박은 이취가 나타나고 분질감에 대한 기호 도가 낮아 저장 기간 중 다른 저장 조건에 비해 60일 이후에 는 유의적으로 향, 단맛, 분질감 및 전체적인 기호도에서 낮은 기호도를 나타냈으며, 대조구인 실온에서는 90 일까 지, $12^{\circ} \mathrm{C}$ 는 120 일까지, $8^{\circ} \mathrm{C}$ 에서는 150 일까지 단호박 고유의 식감을 느낄 수 있는 상태가 유지됨을 알 수 있었다.

Table 1. Changes in the sensory evaluation characteristics of mini sweet pumpkins during storage at different temperature conditions

\begin{tabular}{|c|c|c|c|c|c|c|c|}
\hline \multirow[b]{2}{*}{ Evaluation } & \multirow[b]{2}{*}{ Storage condition } & \multicolumn{6}{|c|}{ Storage period (days) 7 scale $(\mathrm{n}=10$ ) } \\
\hline & & $\begin{array}{l}\text { Curing at } 30^{\circ} \mathrm{C} \\
\text { for } 7 \text { days }\end{array}$ & 30 days & 60 days & 90 days & 120 days & 150 days \\
\hline \multirow{4}{*}{ Color } & $8^{\circ} \mathrm{C}$ & \multirow{4}{*}{$5.40 \pm 1.26$} & $5.60 \pm 0.97^{\mathrm{Aabl} 1)}$ & $5.70 \pm 0.67^{\mathrm{Aa}}$ & $5.60 \pm 0.69^{\mathrm{Aab}}$ & $5.30 \pm 0.67^{\mathrm{Aab}}$ & $4.80 \pm 1.13^{\mathrm{Ab}}$ \\
\hline & $12^{\circ} \mathrm{C}$ & & $4.70 \pm 1.06^{\mathrm{Bb}}$ & $5.60 \pm 0.84^{\mathrm{Aab}}$ & $5.90 \pm 0.87^{\mathrm{Aa}}$ & $4.80 \pm 1.54^{\mathrm{Ab}}$ & $4.70 \pm 0.67^{\mathrm{Ab}}$ \\
\hline & $12^{\circ} \mathrm{C}$ plasma curing & & $5.10 \pm 0.73^{\mathrm{ABa}}$ & $5.40 \pm 1.26^{\mathrm{Aa}}$ & $4.90 \pm 0.88^{\mathrm{Aa}}$ & $4.80 \pm 1.13^{\mathrm{Aa}}$ & $4.50 \pm 0.97^{\mathrm{Aa}}$ \\
\hline & control & & $5.10 \pm 0.56^{\mathrm{ABa}}$ & $5.10 \pm 0.87^{\mathrm{Aa}}$ & $5.00 \pm 0.82^{\mathrm{Aab}}$ & $4.50 \pm 1.43^{\mathrm{Aab}}$ & $4.10 \pm 0.99^{\mathrm{Ab}}$ \\
\hline \multirow{4}{*}{ Flavor } & $8^{\circ} \mathrm{C}$ & \multirow{4}{*}{$5.20 \pm 0.79$} & $5.10 \pm 1.10^{\mathrm{Aa}}$ & $5.20 \pm 1.22^{\mathrm{Aa}}$ & $4.90 \pm 0.73^{\mathrm{Aa}}$ & $4.80 \pm 1.47^{\mathrm{Aa}}$ & $4.70 \pm 0.82^{\mathrm{Aa}}$ \\
\hline & $12^{\circ} \mathrm{C}$ & & $5.00 \pm 0.47^{\mathrm{Aab}}$ & $5.30 \pm 0.95^{\mathrm{Aa}}$ & $5.00 \pm 1.05^{\mathrm{Aab}}$ & $4.40 \pm 1.07^{\mathrm{Abc}}$ & $4.00 \pm 0.67^{\mathrm{Bc}}$ \\
\hline & $12^{\circ} \mathrm{C}$ plasma curing & & $4.80 \pm 0.63^{\mathrm{Aa}}$ & $5.10 \pm 1.19^{\mathrm{Aa}}$ & $4.50 \pm 1.17^{\mathrm{Aa}}$ & $4.20 \pm 1.54^{\mathrm{Aa}}$ & $2.60 \pm 0.97^{\mathrm{Cb}}$ \\
\hline & control & & $5.00 \pm 0.67^{\mathrm{Aa}}$ & $4.40 \pm 1.51^{\mathrm{Aa}}$ & $4.30 \pm 1.25^{\mathrm{Aa}}$ & $4.20 \pm 1.03^{\mathrm{Aa}}$ & $3.10 \pm 0.73^{\mathrm{Cb}}$ \\
\hline \multirow{4}{*}{$\begin{array}{c}\text { Sweet } \\
\text { taste }\end{array}$} & $8^{\circ} \mathrm{C}$ & \multirow{4}{*}{$5.00 \pm 0.67$} & $5.70 \pm 0.82^{\mathrm{Aa}}$ & $6.10 \pm 0.57^{\mathrm{Aa}}$ & $4.80 \pm 0.49^{\mathrm{ABb}}$ & $4.40 \pm 0.96^{\mathrm{ABb}}$ & $4.40 \pm 1.07^{\mathrm{Ab}}$ \\
\hline & $12^{\circ} \mathrm{C}$ & & $5.10 \pm 1.19^{\mathrm{Aab}}$ & $5.40 \pm 0.52^{\mathrm{Aa}}$ & $4.70 \pm 1.25^{\mathrm{ABab}}$ & $4.60 \pm 0.97^{\text {Aab }}$ & $4.30 \pm 0.67^{\mathrm{Ab}}$ \\
\hline & $12^{\circ} \mathrm{C}$ plasma curing & & $5.70 \pm 0.67^{\mathrm{Aa}}$ & $6.10 \pm 0.87^{\mathrm{Aa}}$ & $3.40 \pm 1.50^{\mathrm{Bb}}$ & $2.80 \pm 1.13^{\mathrm{Cb}}$ & $1.70 \pm 0.82^{\mathrm{Bc}}$ \\
\hline & control & & $5.50 \pm 0.71^{\mathrm{Aa}}$ & $5.10 \pm 1.45^{\mathrm{Aa}}$ & $5.00 \pm 0.67^{\mathrm{Aa}}$ & $3.70 \pm 0.82^{\mathrm{BCb}}$ & $2.20 \pm 1.39^{\mathrm{Bc}}$ \\
\hline \multirow{4}{*}{ Mealiness } & $8^{\circ} \mathrm{C}$ & \multirow{4}{*}{$6.50 \pm 0.85$} & $5.90 \pm 0.74^{\mathrm{Aa}}$ & $5.40 \pm 0.84^{\mathrm{ABab}}$ & $5.20 \pm 0.91^{\mathrm{Aab}}$ & $5.10 \pm 0.57^{\mathrm{Aab}}$ & $5.00 \pm 1.05^{\mathrm{Ab}}$ \\
\hline & $12^{\circ} \mathrm{C}$ & & $5.10 \pm 0.74^{\mathrm{Bab}}$ & $5.60 \pm 0.97^{\mathrm{Aa}}$ & $5.10 \pm 0.57^{\mathrm{Aab}}$ & $4.90 \pm 1.19^{\mathrm{ABab}}$ & $4.30 \pm 0.95^{\mathrm{ABb}}$ \\
\hline & $12^{\circ} \mathrm{C}$ plasma curing & & $5.30 \pm 0.67^{\mathrm{Ba}}$ & $4.20 \pm 1.03^{\mathrm{Bb}}$ & $3.70 \pm 1.56^{\mathrm{Bb}}$ & $3.50 \pm 1.27^{\mathrm{Bb}}$ & $1.90 \pm 0.99^{\mathrm{Cc}}$ \\
\hline & control & & $4.90 \pm 0.31^{\mathrm{Ba}}$ & $5.20 \pm 0.79^{\mathrm{ABa}}$ & $5.10 \pm 0.87^{\mathrm{Aa}}$ & $4.30 \pm 1.06^{\mathrm{ABa}}$ & $3.10 \pm 1.72^{\mathrm{Bb}}$ \\
\hline \multirow{4}{*}{ Overall acceptability } & $8^{\circ} \mathrm{C}$ & \multirow{4}{*}{$5.83 \pm 0.42$} & $5.64 \pm 0.94^{\mathrm{Aa}}$ & $5.50 \pm 1.07^{\mathrm{ABa}}$ & $5.12 \pm 0.52^{\mathrm{Aa}}$ & $4.94 \pm 0.67^{\mathrm{Aa}}$ & $4.94 \pm 0.67^{\mathrm{Aa}}$ \\
\hline & $12^{\circ} \mathrm{C}$ & & $5.40 \pm 0.51^{\mathrm{ABa}}$ & $5.70 \pm 0.94^{\mathrm{Aa}}$ & $5.30 \pm 1.25^{\mathrm{Aa}}$ & $4.90 \pm 0.73^{\text {Aab }}$ & $4.30 \pm 0.48^{\mathrm{Bb}}$ \\
\hline & $12^{\circ} \mathrm{C}$ plasma curing & & $5.80 \pm 0.42^{\mathrm{Aa}}$ & $4.30 \pm 1.34^{\mathrm{Bb}}$ & $3.80 \pm 1.39^{\mathrm{Bb}}$ & $2.80 \pm 0.79^{\mathrm{Bc}}$ & $1.90 \pm 0.99^{\mathrm{Cc}}$ \\
\hline & control & & $5.10 \pm 0.56^{\mathrm{Ba}}$ & $5.00 \pm 0.94^{\mathrm{ABa}}$ & $4.50 \pm 1.84^{\mathrm{Aa}}$ & $3.50 \pm 0.97^{\mathrm{ABb}}$ & $2.10 \pm 0.74^{\mathrm{Cc}}$ \\
\hline
\end{tabular}

${ }^{1) a b}$ Means followed by the same letters within the row of each storage condition are not significantly different $(\mathrm{p}<0.05)$; ${ }^{\mathrm{AB}}$ means followed by the same letters within the row per storage period are not significantly different $(p<0.05)$. 


\section{요 약}

가을작형 억제재배한 미니단호박(품종 보짱)을 수확하 여 세척 후 산지 저장고에서 $30^{\circ} \mathrm{C}, 7$ 일간 큐어링 처리하였 고, $8{ }^{\circ} \mathrm{C}, 12^{\circ} \mathrm{C}, 12^{\circ} \mathrm{C}$ 플라즈마 큐어링 및 대조구(실온) 네 가지 조건에서 180 일간 저장하면서 30 일 간격으로 시료를 취해 상품성, 부패율, 수분함량, 경도, 과피 및 과육 색도, 가용성고형분, 전분질함량 및 관능평가의 품질 특성을 비 교분석하였다. 네 처리구 모두 저장 120 일까지 부패율이 없었고 상품성을 유지하였다. 대조구에서는 120 일까지, 1 $2{ }^{\circ} \mathrm{C}$ 에서는 90 일까지 상품성이 4 이상 우수하였다. 부패율은 대조구에서 120 일 이후에 급격하게 증가하여 $70 \%$ 이상이 었으며, $12^{\circ} \mathrm{C}$ 에서는 $20 \sim 60 \%$ 였고, $8^{\circ} \mathrm{C}$ 와 $12^{\circ} \mathrm{C}$ 플라즈마 큐 어링 처리에서는 저장 150 일 동안 부패율은 나타나지 않았 다. 저장 중 수분함량은 $8^{\circ} \mathrm{C}$ 저장에서 가장 낮았으며, 과육 의 적색도는 $12^{\circ} \mathrm{C}$ 및 $12^{\circ} \mathrm{C}$ 플라즈마 큐어링에서 높게 나타 났고, 과피의 녹색도는 저장기간 중 $8^{\circ} \mathrm{C}$ 및 $12^{\circ} \mathrm{C}$ 플라즈마 큐어링 조건에서 높게 나타났으며, 대조구 및 $12^{\circ} \mathrm{C}$ 에서는 저장기간 중 진한 녹색이 황색으로 변하였다. 저장 초기에 는 대조구 및 $12^{\circ} \mathrm{C}$ 플라즈마 큐어링 조건에서 높은 경도를 나타냈으나, 저장기간이 길수록 $8^{\circ} \mathrm{C}$ 가 높게 나타났다. 가용 성 고형분 및 전분질 함량은 저장 90 일까지 증가하다가 그 이후는 감소하였으며, $8^{\circ} \mathrm{C}$ 에 저장한 단호박이 장기간동 안 전분질을 가장 잘 유지하였다. 관능평가시 색, 맛, 분질 감, 전체적 기호도는 $8^{\circ} \mathrm{C}, 12^{\circ} \mathrm{C}$, 대조구, $12^{\circ} \mathrm{C}$ 플라즈마 큐어 링 저장조건 순서로 저장 중 단호박의 기호도가 높게 유지 되었다.

\section{감사의 글}

본 연구는 농촌진흥청 지역특화작목기술개발 연구비로 수행되었음(No. PJ00942703).

\section{References}

1. Oh JY, Kim SM, Yoon JE, Jin YX, Cho YS, Choi YM (2014) Comparison of nutritional compositions of five pumpkin cultivars. Korean J Food Preserv, 21, 808-814

2. Kim SN (2002) Development of processing technology and storage condition for buttercup squash. Final Report of IPET, IPET 02-0340-0217-02, p 18-20

3. Bae JH, Woo HS, Jung IC (2006) Rheological properties of dough and quality characteristics of bread added with pumpkin powder. Korean J Food Culture, 21, 311-318 4. Park JH, Choi JE, Lee JH (2015) Selected physicochemical and consumer preference characteristics of noodles incorporated with sweet pumpkin powder. J Korean Soc Food Sci Nutr, 44, 291-295

5. Lee JH, Lee MK (2013) Quality characteristics of jelly incorporated with sweet pumpkin powder. J Korean Soc Food Sci Nutr, 42, 139-142

6. Jeong KY (2010) Quality characteristics of sulgidduk with concentrated sweet pumpkin powder. MS Thesis. Sunchoun University, Koera, p 45

7. An YH, Lee IS, Kim HS (2011) Quality characteristics of sikhye with varied levels of sweet pumpkin during storage. Korean J Food Cookery Sci, 27, 803-814

8. Park ID (2012) Effects of sweet pumpkin powder on quality characteristics of cookies. Korean J Food Culture, 27, 89-94

9. Jung HA, Kim AN, Ahn EM, Kim YJ, Park SH, Lee JE, Lee SM (2011) Quality characteristics of curd yogurt with sweet pumpkin. Korean J Food Preserv, 18, 714-720

10. Lee MH, Lee SY, Lee SA, Choi YS (2010) Physicochemical characteristics of rice flour sponge cakes containing various levels of pumpkin flour. J Korean Soc Food Sci Nutr, 23, 162-170

11. Lee SM, Joo NM (2007) The optimization of muffin with the addition dried sweet pumpkin powder. J Korean Dietetic Association, 13, 368-378

12. Bae JH, Woo HS, Jung IC (2006) Rheological properties of dough and quality characteristics of bread added with pumpkin powder. Korean J Food Culture, 21, 311-318

13. Heo SJ, Kim JH, Kim JK, Moon KD (1998) The comparison of food constituents in pumpkin and sweet-pumpkin. Korean J Dietary Culture, 13, 91-96

14. Jang MH (2015) Jeollanam-do Agricultural Research and Test Research Plan. Horticultural Research Institute, Jeollanamdo Agricultural Research and Extension Services, Najusi, Korea, p 294-296

15. Jang SW (2003) Studies on development of cultivation technology of high quality fruit of summer squash for exportation. Final reprot of RDA, Gyeonggi-do agricultural research and extension, Northern Agric experiment station, Korea, p 64

16. Han JS, Chung MC, Kim SR (2007) Effect of storage conditions on qualities of buffercup squash (Kabocha). Korean J Food Sci Technol, 39, 644-65

17. Lee JW, Lee JH, Alexander Jeol G. Bibe (2009) Effects of storage temperature and periods on the fruit characteristics in winter squash Bochang. Korean J Hort Sci Technol, 27(SUPPL. I) May 74 
18. Oh BY (2014) Semi-forcing cultivation mini-pumpkin harvesting time and ripening conditions. RDA of Korean Agricultural Handbook. http://www 2.rda.go.kr-farming -farming- list-asp.

19. Han SK, Song YS, Lee HU, Ahn SH, Yang JW, Lee JS, Chung MN, Suh SJ, Park KH (2013) Difference of starch characteristics of sweetpotato (Ipomoea batatas (L.) Lam) by cultivated regions. Korean J Food Sci Technol, 45, 682-692

20. Jung CY, Choi LG (2009) SPSSWIN for Statistics
Analysis, version 14.0 5th ed. Muyok Publishers, Seoul, Korea, p 276-283

21. Mosquera IM, Guerrero LG (1995) Disapperance of chloropyllys and carotenoids during the ripening of the olive. J Sci Food Agric, 69, 1-6

22. Kim SR, Ha TY, Song HN, Kim YS, Park YK (2005) Comparison of nutritional composition and antioxidative activity for Kabocha squash and pumpkin. Korean J Food Sci Technol, 37, 171-177 